\title{
Adopt Effective Competitive Strategies in Response to Environmental Challenges for National Public Broadcasting Corporation in Developing Countries: A Participatory Approach
}

\author{
Mumeka Walumweya' ${ }^{1}$ Jackson Phiri ${ }^{2}$ \\ ${ }^{1}$ Graduate School of Business, University of Zambia, Lusaka, Zambia \\ ${ }^{2}$ School of Natural Sciences, Dept. of Computer Science, University of Zambia, Lusaka, Zambia \\ Email: mumekawalumweya@gmail.com, jackson.phiri@cs.unza.zm
}

How to cite this paper: Walumweya, M., \& Phiri, J. (2022). Adopt Effective Competitive Strategies in Response to Environmental Challenges for National Public Broadcasting Corporation in Developing Countries: A Participatory Approach. Open Journal of Business and Management, 10, 175-191.

https://doi.org/10.4236/ojbm.2022.101011

Received: October 26, 2021

Accepted: January 9, 2022

Published: January 12, 2022

Copyright $\odot 2022$ by author(s) and Scientific Research Publishing Inc. This work is licensed under the Creative Commons Attribution International License (CC BY 4.0).

http://creativecommons.org/licenses/by/4.0/

\begin{abstract}
One of the challenges presented by a dynamic environment is increased competition. External environmental changes have a significant impact on the survival and success of an organisation. To survive the volatile, unpredictable and highly competitive business environment, it is necessary for an organisation to understand the underlying sources of competitive pressure in its industry in order to formulate appropriate effective strategies to respond to the competitive forces. The study sought to determine how environmental factors affected the competitiveness of the Zambia National Broadcasting Corporation and propose effective competitive strategies to employ. The study was conducted within Lusaka at ZNBC and its key stakeholders. The study utilized a mixed methods research methodology. Questionnaires were used as a research instrument for collecting data from Senior, Middle and Supervisory management roles. Systematic, purposive and snowball sampling techniques were used to select a sample size of 135 respondents. The questionnaires were distributed to 135 people and 111 questionnaires were returned. The data collected using the questionnaire was analyzed using descriptive analysis and inferential statistics (Regression). Inferential statistics was used to determine the relationships between the variables. Seven hypotheses were accepted as they showed a statistically significant relationship between the variables of which they had a $p$-value of $\leq 0.05$.
\end{abstract}

\section{Keywords}

Competition, Effective Competitive Strategies, Porters' Five Forces, ZNBC 


\section{Introduction}

In the contemporary environment, Pretorius (2008) observed that intense competitive forces have exerted pressure on firms to innovate ways of enhancing their performance and competitive advantage. Therefore, every firm competing in an industry has a competitive strategy, whether it explicitly developed through a planning process or may have evolved implicitly through the various activities of the various functional departments (Porter, 1980). Developing a competitive strategy is developing a broad formula for how a business is going to compete, what its goals should be and what policies will be needed to carry out those goals. Strategy implies exploitation of unique advantages of the organization in facing the challenges of the environment (Ramaswamy \& Namakumari, 1996). In addition, competitive strategies are designed to give firms an understanding of the changes in the environment and a view of the opportunities available to the firm and quick response to any barriers arising. Firms pursue pace keeping by creating better use of their resources with the aim of achieving sustainability and creating competitive advantage, making them superior to the competing firms (Alnidawi \& Omran, 2016).

Created under the Act of Parliament of 1987, the Zambia National Broadcasting Corporation (ZNBC) is a public broadcasting station intended to serve the needs of the viewing and listening public. Subsequently, ZNBC amendment Act of 2002 section 7, provides for a varied and balanced programming, serving the public interest, and broadcast news and current affairs programmes which must be comprehensive, unbiased, and independent, as well as commentary which shall be clearly distinguished; among many other things. Zambia National Broadcasting Corporation (ZNBC) is the oldest and most dominant market player in the broadcasting industry in Zambia.

The Zambia broadcasting sector was liberalised in 1993 following the enacting of the Zambia National Broadcasting Corporation (ZNBC) Licensing Regulations and the Telecommunications Act in 1994. This liberalization of the media industry led to the introduction of more broadcasting stations. This resulted in industry stiff competition and further made the Corporation struggle to meet the expectations and interests of its various stakeholders even when it has the advantage of being a national broadcaster. Prior to this, only ZNBC radio and television were allowed to provide broadcasting services to citizens.

The liberalization and changes made to some of the media regulations such as digital migration policy, brought about media proliferation and growth which ultimately increased competition in the sector: from a single broadcaster to numerous and various alternative types, media fragmentation and increased spectrum enabling many players into the market. Currently, there are forty-five (45) Television broadcasting stations and more than a hundred and forty (140) Radio stations operating in Zambia (Independent Broadcasting Authority, 2020). Therefore, for the Corporation to survive the competition in the media industry, it has to possess some advantage relative to their competitors. 
This study is significant as it identified current strategies employed by the Zambia National Broadcasting Corporation (ZNBC) and further propose how the Corporation can adopt competitive strategies that can respond to environmental challenges. The study will help top management to implement competitive strategies that will result in the ZNBC having a competitive advantage against its rivals in the industry. Finally, the results of this research shall add to the present literature on the subject of gaining competitive advantage amidst environmental challenges in the broadcasting industry.

In terms of limitations, the study relied more on the Porter's model. Porter's model is formerly based on the economic situation in the 80's with tough competition and comparatively stable market structure; it is not able to consider the new business models and viability of the industries like dynamic market entrants and technological innovations, which will entirely alter the business models within a minor. Therefore, as stated by Kippenberger (1998), it is not prudent to develop strategy only on the basis of Porter's Five Forces Model and should also be examined in addition to other strategic frameworks of SWOT and PESTEL analysis. However, to overcome the above limitation, the study considered the Resource based, Niche and Opportunity based entrepreneurship theories that helped to guide the research.

This research paper strived to investigate how the Public National Broadcaster can adopt effective competitive strategies in response to environmental challenges.

The article is organized as follows:

1) Abstract: giving a brief summary of the study.

2) Introduction: giving an overview picture of the study industry and organisation. The section gives highlights on the importance of the research, limitations and its positive contributions.

3) Literature review: presents the empirical literature and conceptual framework.

4) Research methodology: gives highlights the methodology that was employed to carry out the study, discussing the design, population, data collection methods, techniques, and analysis. The proposed research method, hypothesis and ethical considerations are also covered.

5) Results and discussions: this presents the analysis of the collected data. It interprets, discusses, and concludes the results of the research results.

6) It finally gives a conclusion, limitations, recommendations, conflicts of interest and references.

\section{Literature Review}

Strategy involves an organization deciding where it wants the business to go and how to get there. Strategy is a set of decision-making rules for guidance of organization behavior (Ansoff, 1965). A good strategy is one that could be considered simple, consistent and has a long-term objective. It should be derived 
from a good understanding of the competitive environment through appreciating the dynamics of completion and the challenges in the environment. Strategy guides organizations to superior performance through establishing competitive advantage and acting as a vehicle for communicating and coordinating activities and policies within the organization (Johnson, Scholes, \& Whittington, 2005).

According to Ansoff (1987) to survive and succeed in an industry, the firm must match the aggressiveness of its operating and strategic behaviors to the changeability of demands and opportunities in the market place. There are six factors that define the extent of turbulence in the environment, namely; changeability of the market environment, speed of change, intensity of competitions, fertility of technology, discrimination by customers and pressure from governments and influential groups. Furthermore, Ansoff (1990) suggests that, "the more turbulent the environment is, the more aggressive the firm must be in terms of competitive strategies and changes orientation if it is to succeed". Organizations today operate in a dynamic and constantly changing environment and the purpose of strategy is to exploit the unique advantages of the organization in facing the challenges of the environment (Ramaswamy \& Namakumari, 1996).

\subsection{Empirical Literature}

A number of empirical studies have been carried out on the subject of how an organization can adopt competitive strategies in response to environmental challenges.

Akech, O. Luke (2014) carried out a study to examine response strategies employed by SonySugar Company Limited to address changes emanating from its external environment. The purpose of the research was to find out the response strategies adapted by SonySugar to address changes in its external environment. The research employed case study approach to undertake the exercise. The following were the summaries on the findings based on the objective that guided the study:

1) The study found that environment in the sugar industry and around the SonySugar in particular was experiencing continuous changes. The changes in the company external environment consisted of several but interrelated elements, which included technological changes, social changes, natural weather patterns, the economic climate, legal and political conditions and specific international events among others. Accompanying the changes was threatening challenges and useful opportunities.

2) The study disclosed the following threats; change of climate and weather pattern giving rise to uneven rainfall, increased competition in the sugar industry, legislation which creates liberalization that enhances sugar importation and increasing competition, the entry of new rivals within the company vicinity, technological obsoleteness, change of leadership, and etc. The research noted that the company had a mechanism for detecting changes within its environ- 
ment, and the company had an elaborate way of dealing with threats from the external environment that affected its operation.

3) It was noted that when responding to the changes in the environment, the company did a thorough analysis of the general environment to help ensure that they had fully addressed the current and future changes in the business environment.

In terms of the gaps in this research, the study targeted a few staff in the management team of SonySugar. Therefore, the findings cannot be generalized.

Catherine, K. M. (2016) carried out a study on the challenges of digital broadcasting and competitive strategies adopted by television stations in Kenya. The study was based on a cross sectional survey where the target population was eight well established TV stations in Kenya. Questionnaires were used to collect the data from the eight television stations. The key findings were that:

1) Digital broadcasting had negatively affected the revenue stream of television stations as determined by Porter's Five Forces model due to the increase in the number of television channels available for viewers hence fragmenting the audience. In addition, outdoor advertising companies had increased to provide advertising that captured the much-sought mass audience by the advertisers, and television stations that provided equally attractive products had increased the competitive rivalry. Furthermore, buyers could easily drive prices down. The television station power had reduced which in turn had a negative impact on profitability.

2) Market segmentation was identified to be another indicator of competitive advantage of the television stations as they had specialized markets that targeted particular groups of people. For example, television programmes were either in English or Kiswahili. They also targeted audiences that were accessed through their mobile phones. Various programmes were also designed according to age, gender among others.

3) Resources of the firm were found to be of immense importance in achieving competitive advantage. Some of the key areas were hiring a competitive human resource and giving them regular training, encouraging teamwork and innovation, and investing in information technology. This was found to be possible only if the firm had financial capability.

In terms of research gaps, the study indicated having considered a sample of 42 respondents from eight (8) television stations of which only 36 were returned. Therefore, the sample size was limited to the industry players only and the findings can not be generalized.

Christopher, M. I., Mucheru, S. M., Evans, N. M., Julius, M. B., \& Gongera, E. G. (2014) carried a study on the application of Porter's Five Forces Model on organisation performance: A case of Cooperative Bank of Kenya Ltd. The study found a strong positive relationship between Porter's Five Forces Model and the performance of Cooperative Bank of Kenya.

The study was narrowed to employees of the Bank only. Therefore, the study 
can not be generalized.

Njaaga, E. N. (2013) competitive strategies adopted by Television Broadcasting Media Stations in Kenya. The study found that the television media stations were using cost leadership and differentiation competitive strategies. In addition, the dimensions of competition for television media stations were threat of new entrants, threat of substitutes, power of suppliers, bargaining power of buyers and intensity of rivalry.

The research did not indicate the sampling technique formula used and also the 14 number of respondents was too small to generalize the study.

Osman, W. C. (2018) carried out a study on the competitiveness in the telecommunication sector in Kenya using Porters' Five Forces Model. The study intended to use Porter's Five Forces Model to empirically review the competitive structure of the industry and extract key insights for strategically marketing the key payers. The paper empirically reviews important data from publications, published interviews, and Regulatory Authorities reports on the industry. Porter's five forces model was used to analyze the competitiveness of the industry. The study's key findings indicated that Porters five forces model offered both positive and negative impact to the players in the industry. Companies with less market share were most affected due to the struggle to match the market leaders. The impact of the five forces model was vital for the formulation of business competitive strategies by players in the telecommunication industry.

In terms of gaps; even though (Porter, 2000), alluded to the fact that the model helps a company assess the potential profitability of a particular industry, (Mauri \& Michaels, 1998; Rumelt, 1991) argue that the profitability does not depend on industry-wide factors; firm-specific factors such as unique endowment, individual competence, and strategies are more important to the profitability of the business. The Porter model also indicates that five forces apply equally to all firms in an industry but in reality, the strength of those forces may vary from business to business in terms of size or strength of brand name (Stonehouse \& Snowdon, 2007).

\subsection{Conceptual Framework}

For the purpose of this study, a framework was developed to assist with the process of the research. ZNBC as a public broadcaster performs operational functions such as education, provision of information and entertainment. The institution also performs administration functions such as economic coverage, political coverage, social coverage and cultural coverage. In order to effectively and efficiently perform these operational and administration functions, the Corporation has to be financially viable and have adequate resources in form of systems, infrastructure, skilled labour force, tools, information communications technology, policies, and adequate regulations.

ZNBC makes its revenue through running clients' adverts, selling tapes with documentaries/music and a percentage receipt of Television Levy from Inde- 
pendent Broadcasting Authority (IBA). The entry of private media broadcasting houses into the broadcasting market, the non-receipt of a steady grant from the Government of the Republic of Zambia, the devolving of Television Levy collection from ZNBC to IBA, and the non-receipt of dividends from MultiChoice Zambia, has resulted in the Corporation facing pressure and operational challenges in terms of sustainability, existence and competitiveness.

Due to both internal and external environmental forces exerting on the operational, sustainability, and existence of ZNBC, the study of the competitiveness of the broadcasting industry was necessary. The understanding of these competitive forces using the Porters' Five Forces Tools and SWOT Analysis could make ZNBC gain competitive advantage and be able to compete with private media broadcasting houses on the market. Figure 1 below shows the conceptual framework of this study.

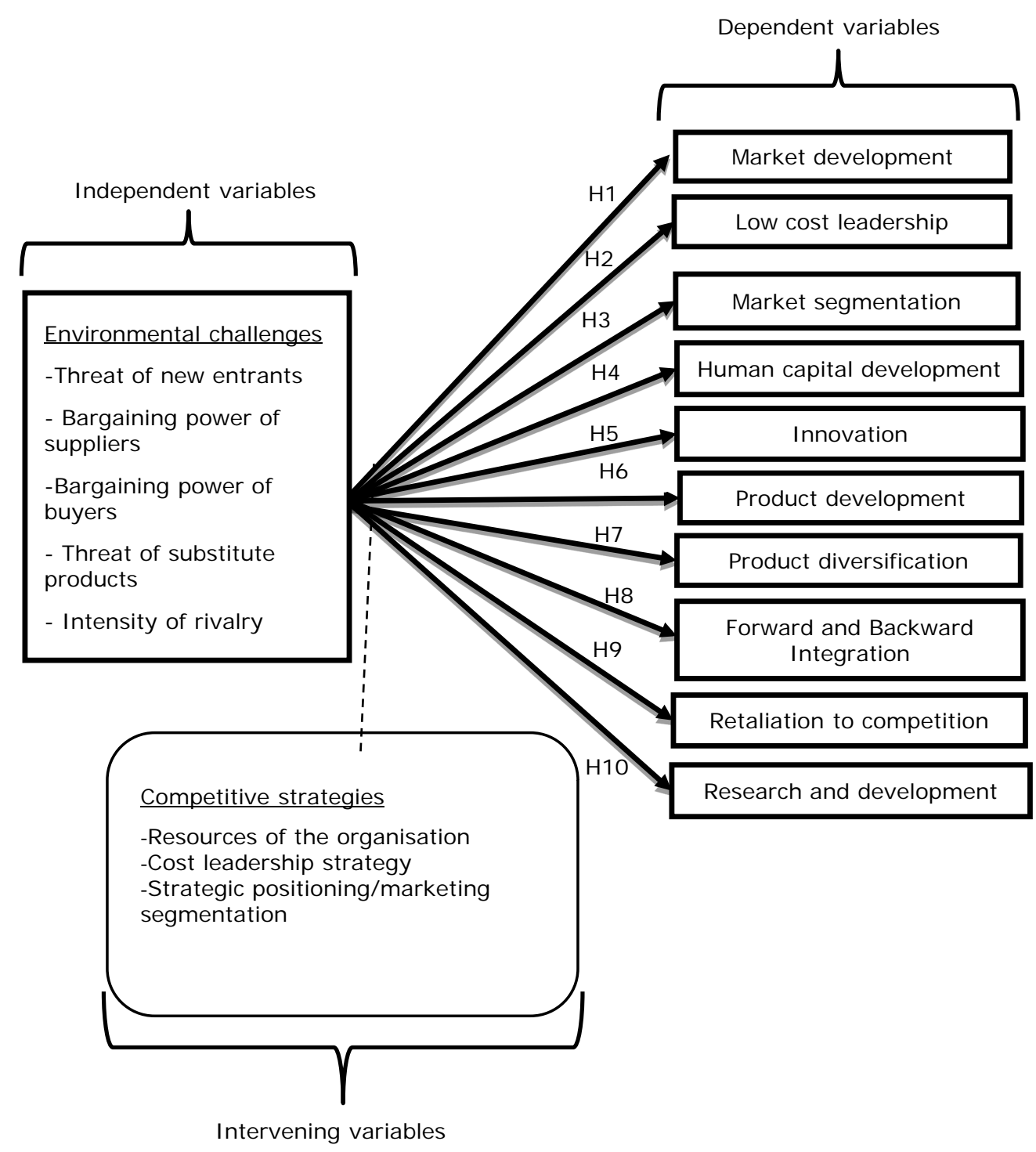

Figure 1: Conceptual framework. Source: Author 2021. 


\section{Research Methodology}

This study employed a participatory approach using two research designs: descriptive and explanatory with quantitative and qualitative methods (mixed methods approach) to carry out the study. This type of a research design is appropriate because it underscores specific predictions, narrations of facts and characteristics regarding individuals, situations or groups. Descriptive survey was used to describe and interpret data about the sample while explanatory was adopted generally to establish a causal relationship between two variables Environmental Challenges as the independent and Effective Competitive Strategies as dependent.

The qualitative approach involved collection of extensive narrative data in order to gain insights into phenomena of interest with the use of open-ended questions to the key selected informants. Graham (2006) points out that, "qualitative approaches endeavours to reveal or understand human attributes, attitudes or behaviour in a more exploratory or interpretative way".

According to Herbert (1990), "quantitative approaches involve the use of standardized measures, numbers and statistics". Quantitative data was used to incorporate some value assumptions and test the three research questions. Quantitative data was analysed using Descriptive statistics (Simple Frequency Tables and Descriptive Statistics) and Inferential Statistics (Simple Regression).

The study was conducted based on the collection of both primary and secondary data. Primary data was collected by using semi-structured interviews and a well-structured questionnaire involving relevant questions regarding how $\mathrm{ZNBC}$ can adopt competitive strategies in response to environmental challenges. The questionnaire was utilized to allow the response of the respondents in a standard and direct way, unbiased approach and objective oriented questionnaire was preferable data gathering tool for this research from middle and senior management employees in selected quasi institutions that are key external stakeholders, those that frequently advertise on the ZNBC platforms, and private Television and Radio Stations. Further, though under strict COVID-19 regulations observations, one on one interviews was conducted to gather information on the subject from supervisors in lower management, middle management and senior management employees at ZNBC Mass Media Complex. The catchment area for this research was the Lusaka Province. The target population comprised 208 respondents based in the Lusaka Province. These were from supervisory roles, middle management and senior management where, 136 employees were from quasi government Institutions, 20 from government Institution (Ministry of Information and Broadcasting Services) and 52 from private Televisions and Radio Stations based in the Lusaka Province. The choice of the respondents was based on their roles and positions in their various organisations. Systematic stratified Purposive (judgment), and snowball sampling technique. Yamane Formula was used to determine the number of respondents to be included in the sample as interpreted below: 


$$
n=\left\{(N) /\left(1+N \varepsilon^{2}\right)\right\}
$$

$N=$ Population of primary and secondary stakeholders based in the Lusaka Province (208)

$\varepsilon=$ Adjust margin of error $[\varepsilon=((p e) / t)]$

$e=$ the degree of accuracy expressed as a proportion (0.05)

$p=$ the number of standard deviations that would include all possible values in the range (2)

$t=t$-value for the selected alpha level or confidence level at 95\% gives 1.96

$$
\begin{gathered}
\square \varepsilon=((2 \times 0.05) / 1.96)=0.051 \\
n=208 /(1+208(0.051 \times 0.051)) \square n=135
\end{gathered}
$$

Therefore, 135 questionnaires were distributed, 111 were fully completed and returned representing an $82 \%$ response rate. Any response rate above $70 \%$ is good (Mugenda \& Mugenda, 2008).

\section{Data Collection and Analysis}

This study employed a methodological triangulation involving survey questionnaires as well as In-Depth Interviews to gather research data. The questionnaire comprised dimensions articulated in line with the conceptualization of the problem statement of this study. Each dimension included a number of items gathered from the literature and these items were measured with Likert scale in terms of its anchors of strongly disagree (1), disagree (2), neither agree nor disagree (3), agree (4) and strongly agree (5). The questionnaire was divided into four parts, namely, Part One, Part Two, Part Three and Part Four. Part One centered on the biographical data and included age, gender, highest qualification, type of employment, grade position and employment sector. Part Two covered issues pertaining to identification of environmental challenges. Part Three looked at competitive strategies and Part Four looked at effectiveness of strategies.

Based on the study the following hypotheses were formulated; that

There was a relationship between:

H1a: Environmental factors and market segmentation $(\mathrm{H} 1)$,

H2a: Environmental factors and low cost leadership (H2),

H5a: Environmental factors and innovation (H5),

H6a: Environmental factors and product development (H6),

H7a: Environmental factors and product diversification (H7),

H8a: Environmental factors and forward \& backward integration (H8), and

$\mathrm{H} 10 \mathrm{a}$ : Environmental factors and research \& development (H10).

The other three comprising environmental factors and market segmentation (H3), environmental factors and human capital (H4), and environmental factors and retaliation to competition \& defence moves (H9); established that there was no relationship. 
Descriptive statistics and Regression Analysis were done using Statistical Package for Social Sciences (SPSS) Version 16.0 and Microsoft Excel. Qualitative data analysis was done by firstly categorizing data into themes, which was later coded. Some responses were recorded verbatim for the production of verbal synthesis collected from narratives of open and ended questions (Kazonga, 2019).

\section{Results and Discussions}

This section analyses, interprets and presents the results of this study using the data that was collected. It presents data collected from a descriptive sample survey and explanatory study design which was conducted to devise competitive strategies that the Zambia National Broadcasting Corporation can adopt in response to environmental challenges.

Data was analyzed using descriptive analysis and Pearson correlation coefficient was used to determine the relationship between the variables.

\subsection{Basic Statistical Analysis}

Out of 135 questionnaires that were distributed, 111 questionnaires were completed and returned therefore, representing an $82 \%$ response rate (Table 1).

The statistical results in terms of gender distribution were that, $52 \%$ of respondents represented the male gender and $48 \%$ represented the female gender. This is shown in Figure 2 below.

In terms of age distribution, the majority of respondents fell in the group category of " 41 - 50" years giving a percentage of 62.2 against the total respondents. The age group category of " 31 - 40 " was second with $21.6 \%$. The age group category of " $51-60$ " was third with $9.9 \%$ and fourth was the age distribution of " 21 - 30" years with the lowest number of respondents at $6.3 \%$. See Figure 3 below.

Largely, the level of education has a direct connection to how people can analyse issues. In this study, the different qualifications level attained by the respondent was considered in order to obtain divergent views and responses on the

Table 1. Questionnaires.

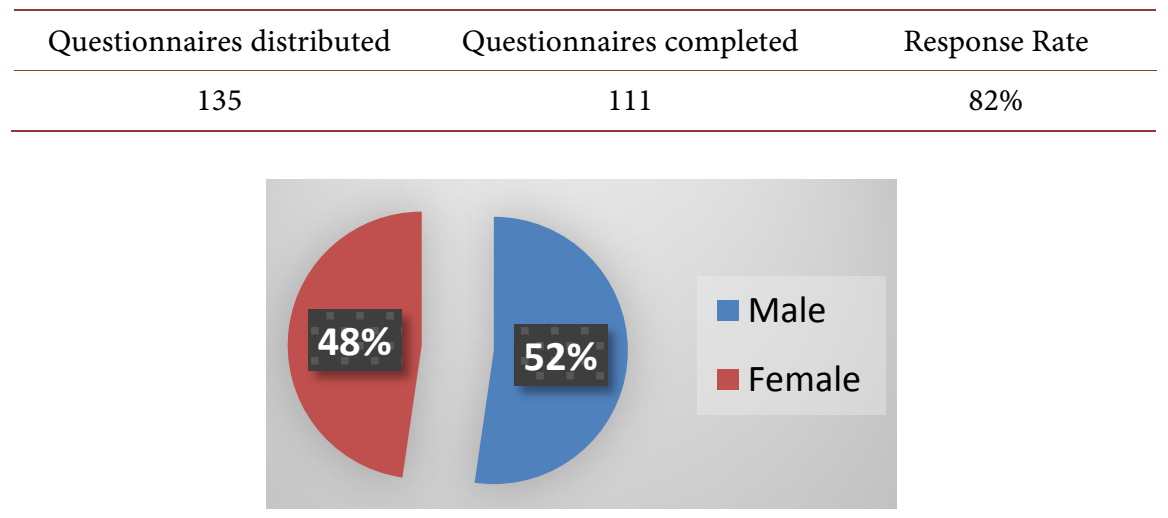

Figure 2. Gender of respondents. 


\section{Age}

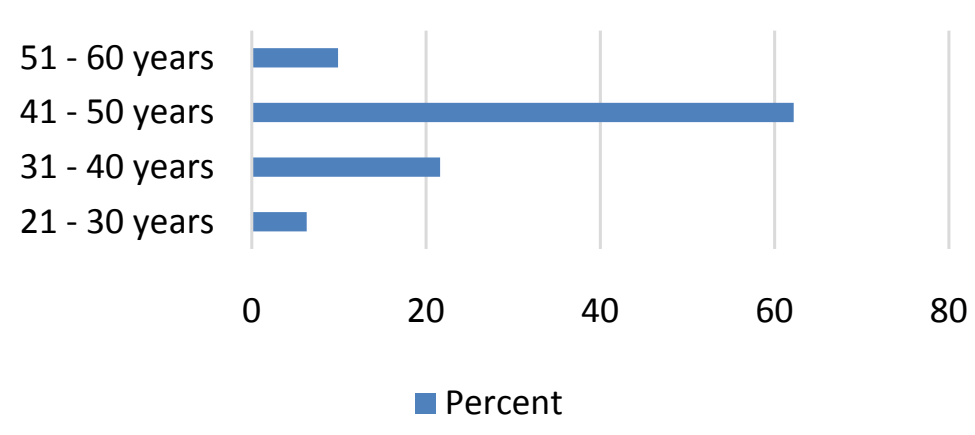

Figure 3. Age respondents.

study. Results obtained indicated that the highest number of individuals were Masters holders comprising $45.9 \%$ of the sample, followed by the University Degree holders comprising $35.1 \%$. Diploma holders were third with $16.2 \%$, while Certificate and below were fourth with $2.7 \%$. See Figure 4 below.

The study analyzed the employment type of respondents. The study indicated that $50.5 \%$ were pensionable, while $49.5 \%$ were contractual.

In terms of grade position, as per Figure 5 below, the highest number of respondents were from the Middle Management Position with 53.2\%. The second was the Senior Management with $28.8 \%$ and third was Lower Management (Supervisory) with $18.0 \%$.

In terms of employment sector, $41.4 \%$ were respondents working for quasi-government organisation. $37.8 \%$ of respondents were from the private institutions and $20.7 \%$ of the respondents were from public organisations.

\subsubsection{Reliability and Validity}

The researcher gauged the clarity and relevance of the research instruments so that questions found to be inadequate were either discarded or modified in order to improve the quality of the instruments of data collection. To test a questionnaire, a quick pilot study was done to correct errors, gain consistency in the flow of questions as well as a rehearsal. In this case, reliability was used as a measure of the extent to which a questionnaire produces similar results on different occasions from the same sample (Kitchens, 2002).

Data collected was also subjected to the principal underlying sampling theory with $+/-0.05 \%$ of margin at $95 \%$ confidence level.

Further, validity in the present study has been considered as the degree to which the survey questionnaire and interview questions would accurately solicit respondents' views. In order to enhance the validity of the research findings, the collected data was verified by using triangulation as well as member checking.

\subsubsection{Testing Hypotheses Correlations}

1) Respondents' identification of environmental challenges: Porters' Five Forces Model 


\section{Education Level}

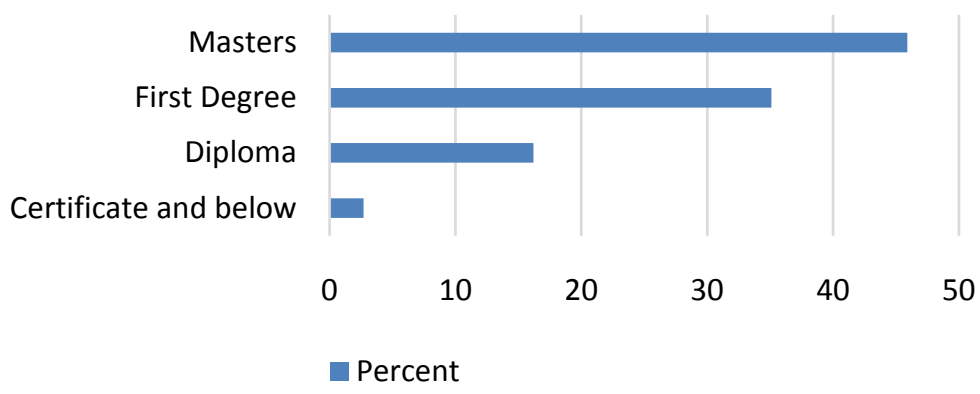

Figure 4. Education level of respondents.

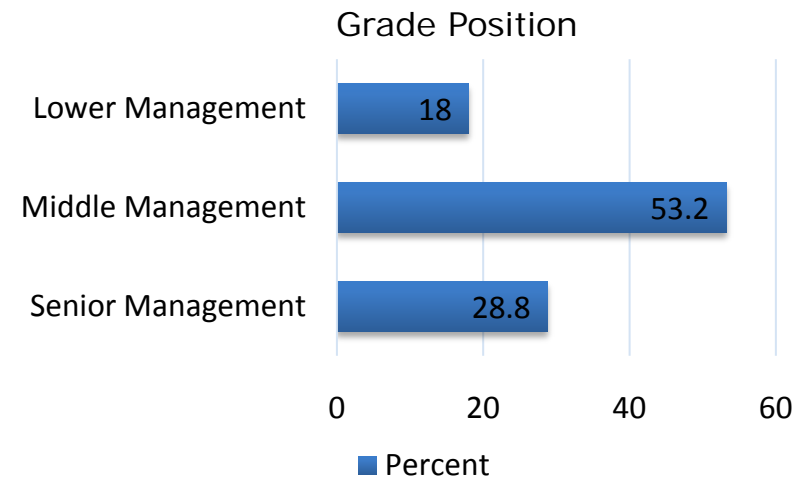

Figure 5. Grade position of respondents.

The study sought to determine how environmental factors affect the competitiveness of the Zambia National Broadcasting Corporation and suggest which competitive strategies can be effective to the competitiveness of ZNBC in the broadcasting industry. Using Porters' Five Forces model that enables an organisation to understand both the strength of a position it is considering moving into, it was revealed that there was high competition in the broadcasting industry (Table 2).

2) Respondents' determination of the extent of competition from private broadcasting houses and their threat on the existence of ZNBC

In terms of resources of the organisation, fifty-six percent of the respondents were of the view that ZNBC works to build good image to the public. This being the highest scored figure, it does not convincingly give a good picture about the organisation in this respect. Forty-three percent of the respondents felt that ZNBC does not ensure adequate training of its staff. A score between a range of thirty-five to forty-seven percent were high scores indicating that respondents did not agree that ZNBC considers the welfare of staff, invests highly in information communication technology, its management encourages teamwork, its management encourages innovation, and there is high level of accountability to boost internal controls.

Concerning cost leadership strategy, respondents were neutral on whether 
Table 2. Summary of respondents' identification of environmental challenges.

\begin{tabular}{|c|c|}
\hline Force & Results \\
\hline New entrants & $\begin{array}{l}\text { Eighty-three percent of respondents indicated the possibility of } \\
\text { new competitors quickly entering the market and eventually } \\
\text { weakening ZNBC position and eighty percent of new firms can } \\
\text { easily enter the broadcasting industry. }\end{array}$ \\
\hline Threat of Substitute & $\begin{array}{l}\text { A score of between seventy to eighty-six percent of the } \\
\text { respondents agreed that introduction of pay broadcasting } \\
\text { stations, introduction of specialized stations, availability of } \\
\text { internet to access information and easy for advertisers to find } \\
\text { new media of advertising; are a threat substitutes. }\end{array}$ \\
\hline $\begin{array}{l}\text { Bargaining power } \\
\text { of suppliers }\end{array}$ & $\begin{array}{l}\text { Forty-seven percent of the respondents disagreed that ZNBC has } \\
\text { a high number of suppliers at its disposal. Fifty-six percent of the } \\
\text { respondents disagreed that ZNBC offers better prices to its } \\
\text { suppliers. }\end{array}$ \\
\hline $\begin{array}{l}\text { Bargaining power } \\
\text { of buyers }\end{array}$ & $\begin{array}{l}\text { Fifty-nine percent of the respondents disagreed that } \mathrm{ZNBC} \text { has a } \\
\text { wide range of programmes for its audience. Sixty-five percent of } \\
\text { the respondents disagreed that } \mathrm{ZNBC} \text { has high quality of } \\
\text { programmes that it provides }\end{array}$ \\
\hline Intensity of rivalry & $\begin{array}{l}\text { Seventy-two percent of the respondents indicated that } \mathrm{ZNBC} \\
\text { programming does not conform to the highest customer } \\
\text { expectations }\end{array}$ \\
\hline
\end{tabular}

ZNBC pursues less costly processes. Thirty-eight percent, which was the high score, indicated that respondents disagreed that the low price of acquiring international programs determines ZNBC purchasing power. Apparently, fifty-seven percent of the respondents were of the view that ZNBC charge advertisers differently. Forty-one percent of the respondents could neither agree nor deny that technology employed by ZNBC aims at low cost production. Cost leadership strategy emphasizes the reduction of costs on products and services in order to gain a large marketplace and profit. Producing quality products and selling them at a lower cost to a large mass increases the revenue, profits, and expands the company business. The benefits of using this strategy may include increase in market size, increase in business sustainability, increase in profit margins, and reduction in competition.

Regarding strategic positioning and market segmentation, forty percent, being the highest score, of the respondents felt that ZNBC does not carry out direct-based marketing (one-to-one marketing). Forty-three percent and fifty-three percent of the respondents felt that ZNBC offers promotions tailored to specific customer groups and ZNBC customizes information to reach particular people, respectively. However, fifty-seven percent disagreed that ZNBC does meet-the-people tour to interact with the people at their residences. Strategic positioning is a company's relative position with its industry in terms of matters surrounding performance. It therefore reflects choices that an organisation 
makes about the kind of value it creates and how that value is differentiated from other rivals. Positioning allows an organisation to claim a specific feature or benefit and focuses their products and services accordingly so that the organisation appear as an expert in the services (Table 3).

3) Respondents' response on devising measures: how the ZNBC can gain competitive advantage against the environmental challenges it is facing

Ten hypothesis were tested using Regression Analysis. It is generally accepted in scientific research that if the $p$-value (Sig.) is lower than 0.05 , then the decision is to accept the hypothesis. Therefore, from Table 4 below, it can be noted that $\mathrm{H} 1, \mathrm{H} 2, \mathrm{H} 5, \mathrm{H} 6, \mathrm{H} 7, \mathrm{H} 8$, and $\mathrm{H} 10$ had p-values of less than 0.05 and the decision was to accept that there was a relationship between the Independent variables

Table 3. Determination of extent of competition by analyzing internal competitive strategies.

\begin{tabular}{ll}
\hline \multicolumn{1}{c}{ Strategy } & \multicolumn{1}{c}{ Results } \\
\hline $\begin{array}{l}\text { Resources of the } \\
\text { organisation }\end{array}$ & $\begin{array}{l}\text { ZNBC works to build good image to the public. This being } \\
\text { the highest scored figure, it does not convincingly give a } \\
\text { good picture about the organisation in this respect. } \\
\text { Forty-three percent of the respondents felt that ZNBC does } \\
\text { not ensure adequate training of its staff. }\end{array}$ \\
\hline $\begin{array}{l}\text { Cost leadership strategy } \\
\text { Thirty-eight percent, which was the high score, indicated } \\
\text { thategic positioning and respondents disagreed that the low price of acquiring } \\
\text { international programs determine ZNBC purchasing power. }\end{array}$ \\
$\begin{array}{l}\text { Forty percent, being the highest score, of the respondents felt } \\
\text { that ZNBC does not carry out direct-based marketing } \\
\text { (one-to-one marketing). }\end{array}$ \\
\hline
\end{tabular}

Table 4. Summary of hypothesis results.

\begin{tabular}{clcc}
\hline Hypothesis & \multicolumn{1}{c}{ Path } & Sig. & Decision \\
\hline H1 & Environmental factors-Market development & 0.000 & Accepted \\
H2 & Environmental factors-Low cost leadership & 0.007 & Accepted \\
H3 & Environmental factors-Market segmentation & 0.353 & Rejected \\
H4 & Environmental factors-Human capital development & 0.251 & Rejected \\
H5 & Environmental factors-Innovation & 0.002 & Accepted \\
H6 & Environmental factors-Product development & 0.002 & Accepted \\
H7 & Environmental factors-Product diversification & 0.016 & Accepted \\
H8 & Environmental factors-Forward and Backward & 0.000 & Accepted \\
& Integration & & \\
H9 & Environmental factors-Retaliation to competition & 0.113 & Rejected \\
H10 & End defensive moves & 0.005 & Accepted \\
\hline
\end{tabular}


and Dependent variables. However, $\mathrm{H} 3, \mathrm{H} 4$, and $\mathrm{H} 9$ had $p$-values higher than 0.05 and the decision was to reject that there was a relationship between the Independent variables and those particular Dependent variables.

\section{Conclusion}

The conclusion is that the broadcasting industry has become competitive in that new competitors can quickly enter the industry; and new firms can easily enter the industry; ZNBC has highly qualified staff; there is introduction of pay broadcasting stations. There is introduction of specialised broadcasting stations; there is availability of internet facilities to access information; and it is easy for advisers to find a new media of billboards. In addition, the ZNBC has a wide geographical coverage; it customizes information to reach particular people; it is easy for advertisers to drive prices down; charges advertisers differently; and the number of competitors has increased and they equally offer attractive products.

Apparently, the ZNBC has not strengthened its ability to retain staff; it has a low number of suppliers to its disposal; does not have better prices to its suppliers; and has a low range of programmes for its audience. In addition, it provides low quality programmes; its programming does not conform to the highest customer expectations; and it does not consult with other broadcasting houses to set prices and programming. Also, it was concluded that ZNBC does not pursue less costly processes; has not employed technology that aims at low cost production; and has no high purchase power in acquisition international products at low cost. It does not carry out direct based marketing (one to one marketing); does not do "meet-the-people" to interact with the people at their residences; and does not offer promotions tailored to specific customers.

\section{Limitations}

The study encountered some limitations mainly due to the sampling technique employed, time constraint and COVID-19 pandemic. Stratified and purposive (judgmental) sampling may not give a sample that is the representative of the population, hence limiting the generalization of the findings and the sample size may not be adequate to draw the conclusions about the population. COVID-19 pandemic also delayed the data collection process because most organisations were not allowing entry to their premises so mostly the interviews were done by telephone, email or simply dropped at the reception to be collected on a later day.

\section{Recommendations}

The Zambia National Broadcasting Corporation should consider employing effective competitive strategies comprising: market development, low cost leadership, innovation, product development, product diversification, forward \& backward integration, and research \& development. 
These strategies will enable ZNBC to conduct audience research, downsizing (reduce wage bill), reduce high production costs, ensure that broadcasting processes are digilitized, invest in new media such as Over-The-Top (OTT) technology (online) \& internet, enhance local content, and restructuring.

The Corporation should implement and closely monitor the 2021-2025 Strategic Plan.

Parliament should revisit the ZNBC (Amendment) Act of 2002 and include clauses that shall detach government control and interference in the administration and operational functions of ZNBC. Therefore, Parliament should directly be responsible for the affairs of $\mathrm{ZNBC}$ as a public broadcaster.

ZNBC Management should devise ways and means of making the Corporation financially stable and come up with acceptable conditions of work such as transport, equipment, specialised training and improved salaries for its employees for the purpose of work efficiency, effectiveness and motivation.

\section{Acknowledgements}

The author would like to acknowledge the invaluable contribution from Dr. J. Mwanza (Lecturer-GSB UNZA), all research participants, the Graduate School of Business faculty, Mr. Michael Lumai (Husband) and Children (Michael, Jane and Maxwell).

\section{Conflicts of Interest}

The authors declare no conflicts of interest regarding the publication of this paper

\section{References}

Akech, O. L. (2014). Response Strategies to Changes in External Environment by Sonysugar Company Limited. Master's Dissertation, University of Nairobi.

Alnidawi, A. B., \& Omran, M. F. (2016). Human Resource Management Activities Adopted in the Value Chain Model and Their Impact on the Organisational Sustainability-An Empirical Study of Jordanian Pharmaceutical Companies. International Business Research, 9, 106-117. https://doi.org/10.5539/ibr.v9n8p106

Ansoff, I. (1965). Competitive Strategy: Analytical Approach to Business Policy for Growth and Expansion. McGraw-Hill.

Ansoff, I. (1987). Corporate Strategy. Penguin.

Ansoff, I. (1990). Implanting Strategic Management. Prentice Hall.

Catherine, K. M. (2016). Challenges of Digital Broadcasting and Competitive Strategies Adopted by Television Stations in Kenya. Master's Dissertation, University of Nairobi.

Christopher, M. I., Mucheru, S. M., Evans, N. M., Julius, M. B., \& Gongera, E. G. (2014). The Application of Porter's Five Forces Model on Organisation Performance: A Case of Cooperative Bank of Kenya Ltd.

Graham, S. (2006). Strategy Instruction and the Teaching of Writing: A Meta-Analysis. In C. A. MacArthur, S. Graham, \& J. Fitzgerald (Eds.), Handbook of Writing Research. The Guilford Press. 
Herbert, B. (1990). Industrialization as an Agent of Social Change: A Critical Analysis. D. R. Maines, \& T. R. Morrione (Eds.). Aldine de Gruyter.

Independent Broadcasting Authority (2020). About Us. https://www.iba.org.zm/about-us/

Johnson, G., Scholes, K., \& Whittington, R. (2005). Exploring Corporate Strategy (7th ed.). Prentice Hall.

Kazonga, E. (2019). A Presentation on Introduction to Data Analysis Packages. University of Lusaka PHD Workshop.

Kippenberger, T. (1998). Strategy According to Michael Porter. The Antidote, 3, 24-25. https://doi.org/10.1108/EUM0000000006625

Kitchens, L. (2002). Exploring Statistics: A Modern Introduction to Data Analysis and Inference. Int'l Thomson.

Mauri, A. J., \& Michaels, M. P. (1998). Firm and Industry Effects within Strategic Management: An Empirical Examination. Strategic Management Journal, 19, 211-219. https://doi.org/10.1002/(SICI)1097-0266(199803)19:3\%3C211::AID-SMJ947\%3E3.0.C $\underline{\mathrm{O} ; 2-\mathrm{T}}$

Mugenda, O. M. \& Mugenda, A. G. (2008). Research Methods: Quantitative and Qualitative Approaches. ACTS Press.

Njaaga, E. N. (2013). Competitive Strategies Adopted by Television Broadcast Media Stations in Kenya. Master's Dissertation, University of Nairobi.

Osman, W. C. (2018). Competitiveness in the Telecommunication Sector in Kenya Using Porters' Five Forces Model. http://euroasiapub.org/current.php?title=IJRFM

Porter, M. E. (1980). Competitive Strategy: Techniques for Analyzing Industries and Competitors. Free Press.

Porter, M. E. (2000). Locations, Clusters, and Company Strategy. In G. Clark, M. Feldman, \& M. Gertler (Eds.), The Oxford Handbook of Economic Geography (pp. 253-274). Oxford University Press.

Pretorius, M. (2008). When Porters' Generic Strategies Are Not Enough. Complementary Strategies for Turnaround Situations. Journal of Business, 29, 19-28. https://doi.org/10.1108/02756660810917200

Ramaswamy, V. S., \& Namakumari, S. (1996). Strategic Planning for Corporate Success. Macmillan India Ltd.

Rumelt, R. P. (1991). How Much Does Industry Matter? Strategic Management Journal, 12, 167-185. https://doi.org/10.1002/smj.4250120302

Stonehouse, G., \& Snowdon, B. (2007). Competitive Advantage Revisited: Michael Porter on Strategy and Competitiveness. Journal of Management Inquiry, 16, 256-273.

https://doi.org/10.1177/1056492607306333 